\title{
A Simple Method to Obtain Microbial-free in vitro Moss Cultures
}

\section{Hanan Shaaban*, Hanaa Shabbara, Mohamed Farag and Wagieh El saadawi}

Botany Department, Faculty of Science, Ain Shams University, Abbasia, Cairo, Egypt.

*Corresponding author: hananshaaban22@yahoo.com

\begin{abstract}
Developing a suitable method for moss sterilization is a crucial step for successful in vitro culture. Different chemical and physical methods have been tried by many authors for more than a century but with low axenic culture percentages. An easy and economic (no use of chemicals or antibiotics) cultivation method is developed here, which proved high success with three moss species starting from gametophores.
\end{abstract}

\section{Key words}

Axenic cultivation, mosses, Bryum, Philonotis, sterilizing agents

\section{Introduction}

Bryophyta is one of the earliest inhabitants of terrestrial environments. They survived and tolerated for ages, various climatic conditions. However, harvesting large quantities of bryophytes for greening and different applications can seriously damage the natural habitat ( Peck and Muir 2001).To avoid or at least minimize such a serious environmental problem an alternative solution exists in the in vitro culture technique which facilitates growing and regenerating plants. In vitro culture of plants including bryophytes furnishes, therefore a good solution for nature conservation. In addition it gives us opportunities to increase our knowledge about certain aspects of plant biology, development (Duckett et al. 2004, Victoria et al. 2011) and biotechnological research (Beike et al. 2010).
Trials for propagation of mosses in pure cultures started a long time ago by pioneer bryologists (e.g. Vöchting 1885, Becquerel 1906) and are still going on till now (e,g. Rowntree and Ramsay 2009, Rowntree et al. 2011, Carey et al. 2015), however the obtained results of survival percentages were poor or at least not satisfactory, particularily when the in vitro culture was started from gametophore tissues and not from spores.

Initiating axenic in vitro cultures from field grown plants requires surfacesterilization of plant part inocula to get rid of superficial contaminants (Basile 1972). As surface sterilization of mature capsules - before dehiscing- is effective, axenic cultures of mosses are most easily established from spores (Duckett et al. 2004, Lal 1984, Reski 1998, Hohe and Reski 2005). Unfortunately, starting cultures from spores is impractical for many species, especially dioicous taxa (ca. $60 \%$ of recorded moss taxa); 


\section{Hanan Shaaban et al.}

Hedenäs and Bisang 2011, which mostly never produce capsules (Glime 2013). Alternatively, gametophores have to be used for producing axenic cultures of the majority of mosses. However, surface sterilization of moss gametophore is usualy ineffective in establishing axenic cultures. Gametophores are very delicate and the phylloids are in general tinny, mono-layered, inhabitated by various xenic organisms like bacteria, algae, protozoa, fungi and others (Vujičić et al. 2009, Sabovljevic et al. 2012). As a result, vegetative fragments may be either killed by the sterilization procedure or by microbes ( Duckett et al. 2004).

Generally, there are many previously described techniques for surfacesterilizing of small parts of moss gametophyte, as washing machine (Basile 1972, Basile and Basile 1988), ultrasound (Cano 1996), and chemicals ( e.g. sodium dichloro-isocyanurate

(SDICN) (Parkinson et al. 1996, Niedz and Bausher 20002, Sarasan et al. 2006, Liang et al. 2010). The survival percentages of sterilized gametophores were $2-11 \%$ with sodium hypochloride $(\mathrm{NaOCl})$ and $37-$ $66 \%$ with sodium dichloroisocyanurate (SDICN) (Sabovljevic et al. 2012) and $70 \%$ with combination between $70 \%$ ethanol for $5 \mathrm{sec}$. and $5 \%(\mathrm{NaOCl}), 30$ sec.

(Liang et al. 2010) [23]. Mercuric Chloride was also used for sterilization of protonema, however it was very harsh and the method has low survival percentage (Chen et al. 2009). Recently, an agar embedding method with antibiotic, significantly reduced the presence of bacterial contaminants in gametophyte tissue (Carey et al. 2015).

However, trials for the development of an easy, convenient, effective and, more successful method for obtaining axenic cultures of different moss species starting from gametophores remain to be a current challenge. This work represents one of these trials, however distinguished because efficient sterilization is sought without using chimicals or antibiotics.

\section{Materials and Methods}

Fresh gametophores of three moss taxa collected from natural habitats in Cairo, Egypt, were used in this experiment. These taxa were Bryum argenteum Hedw. Bryum subapiculatum Hampe (Bryaceae) and Philonotis hastata (Duby) Wijk\& Margad (Bartramiaceae). $B$. argenteum gametophores (given herbarium no. MF 03) were collected in October 2013, from Kobri El-Kobba, underground Metro station, $\mathrm{ca}$. $30^{\circ} 4^{\prime}$ $58.10^{\prime \prime} \mathrm{N}$ and $31^{\circ} 17^{\prime} 32.29^{\prime \prime} \mathrm{E}$, where they grow in shade, on a wet vertical side of a cemented pavement. $B$. subapiculatum gametophores (MF10) were collected in October 2013 from the Botanical Garden of the Faculty of Science, Ain shams University, ca. $30^{\circ} 4^{\prime}$ $40.75^{\prime \prime} \mathrm{N}$ and $31^{\circ} 16^{\prime} 56.03^{\prime \prime} \mathrm{E}$, where they grew exposed to sun, on a wet cemented layer of a sewage drain. Philonotis hastata gametophores (MF14) were collected in November 2013, from Kobri El-Kobba, underground Metro Station, $c a .30^{\circ} 5^{\prime} 4.30^{\prime \prime} \mathrm{N}$ and $31^{\circ} 17^{\prime}$ $42.71^{\prime \prime} \mathrm{E}$, where they grew exposed to sun, on a wet vertical side of a cemented pavement. Both $P$. hastata and $B$. argenteum carried easily detachable bulbils.

The present developed technique is modified from that of (Chen et al. 2009) . The following steps were carried out:

1. Freshly collected small moss samples were carefully cleaned mechanically from sticking soil particles and other impurities and rinsed with distilled 


\section{A Simple Method to Obtain Microbial-free in vitro Moss Cultures}

water and then vortexed three times for 10 minutes each.

2. Individual gametophores were picked up under stereomicroscope (Novex model, Netherlands), then washed and rinsed with sterile distilled water (SD $\mathrm{H}_{2} \mathrm{O}$ ) three times for five minutes each.

3. Washed gametophores of each species were divided into two groups; the first group was propagated in $250 \mathrm{ml}$ conicals, containing $100 \mathrm{ml} \mathrm{SD} \mathrm{H}_{2} \mathrm{O}$, while the second one was propagated in $250 \mathrm{ml}$ transparent plastic containers, containing a thin film ( $5 \mathrm{~mm}$ thick) of sterilized water-saturated soil $(30 \mathrm{~g}$ soil; particles of the size $\leq 300 \mu \mathrm{m}$ ).

4. The former group was kept on the lab bench under low light intensity for four to six weeks. The latter group was incubated in a plant growth chamber (Vision scientific plant growth chamber model V3-DM; Vision Scientific Company Ltd, Korea) for four to six weeks, under controlled conditions of adjusted light/ dark periods (16/8 hrs) using white illumination with intensity of $9200 \mathrm{Lux}$ and fluctuant temperature of 25/ $18^{\circ} \mathrm{C} \pm 2$ for light and dark periods, respectively.

5. The growth medium (water or soil) on which new gametophores were developed faster was considered more suitable for the corresponding species.

6. Newly developed gametophores of $B$. argenteum and $P$. hastata grew faster on water-saturated soil whereas those of B. subapiculatum grew faster in SD $\mathrm{H}_{2} \mathrm{O}$. All gametophores were carefully excised under aseptic conditions.

7. The excised gametophores were gathered, washed twice with $\mathrm{SD} \mathrm{H}_{2} \mathrm{O}$ while shaking, each time, for $5 \mathrm{~min}$. they were then spread on dry sterile filter paper.
8. The gametophores of each species were then divided into six groups. The first 3 groups were cultured on 3 different solid media and the other 3 groups were cultured in 3 different liquid media as one gametophore per each jar in three replicates (i.e. a total of 54 jars for the three species). The composition of the three different solid media was as follows:

i. Nutrient free agar NFA (9 jars for the 3 species).

ii. Half strength Murashige and Skoog miniral salts HsMS (1962) (9 jars for the three species).

iii. Full strength MS mineral salts; FsMS (9 jars for the 3 species).

The composition of the three different liquid media was as follows:

i. Nutrient free liquid medium; NFM(Strelized distilled water) (9 jars for the 3 species).

ii. Half strength Murashige and Skoog mineral salts HsMS (9 jars for the three species).

iii. Full strength MS mineral salts; FsMS (9 jars for the 3 species).

9. The 54 jars were incubated in the plant growth chamber under the previous described conditions (of illumination and temperature) and externally observed weekly for ten weeks. The protonemata and gametophores were examined microscopically afterwards i.e. after incubation for ten weeks.

10. The percentages of survived gametophores i.e. the axenic cultures (growth without any contamination) were calculated.

\section{Observations and Discussion}

Cultures in 45 jars out of 54 jars (i.e., $83.3 \%$ ) were axenic. The percentages of survival with the used technique were mostly higher in liquid media than on solid media (Table 1). The percentages of 


\section{Hanan Shaaban et al.}

survival were $67-100 \%$ for $B$. argenteum, (33-100\%) for B. subapiculatum and (33$100 \%$ ) for P. hastata (Table 1).

These results show almost $100 \%$ success for the axenic cultivation of gametophores in different types of liquid media (NFM, HsMS,FsMS) for the three mosses under investigation. These results are highly promising, compared with the percentages $(5 \%-70 \%)$ of survival of gametophores reported by some authors e.g., (Sabovljevic et al. 2012, Liang et al. 2010) using different sterilizing agents. These results have been achieved, in the present work, due to the attention paid to two points during the in vitro cultivation: 1. Avoidance of sterilizing the cultured and the recultured gametophores by chemicals and 2 . The use of repeatedly cleaned gametophyte tissues for inoculation on nutrient media. Cleaning was achieved by washing several times with SD $\mathrm{H}_{2} 0$ which is considered a modification of the technique that has been used before by (Chen et al. 2009), who used chemicals for the sterilization of the re-cultured gametophores.
In the present work, when the new branches were excised and re-cultured on nutrient media, it was noticed that they grew more successfully than their progenitors. This agrees with results obtained by (Rowntree 2006) who reported that Ditrichum plumbicola Crundw. gametophyte grew significantly better when harvested from recultured non-axenic cultures than from the wild collected material. This might be interpreted on the basis that pre-culturing partially acclimatizes plants to culture conditions, and reduces the number and type of contaminants. Therefore 100\% success is highly expected, using the present technique, if the re-culture step is repeated more than once.

Thus the technique used in the present work not only avoids probabilities of gametophores damage (by sterilizing agents and/or microbes) but also produces luxurious growth. Because contamination was absent in most jars, gametophores had full chance to obtain their required nutrients from the culture medium and grow to form large colonies establishing a good biomass (see figs. 1, 2, 3).

Table (1). Percentages of survival of Bryum argenteum, Bryum subapiculatum and Philonotis hastata in liquid and on solid media: nutrient free medium (NFM), half strength Murashig and skoog (HsMS) medium, full strength Murashig and Skoog (FsMS) medium and nutrient free Agar (NFA) medium.

\begin{tabular}{|l|c|c|c|c|c|c|}
\hline \multirow{2}{*}{\multicolumn{1}{|c|}{ Species }} & \multicolumn{6}{|c|}{ \%o of survival } \\
\cline { 2 - 7 } & \multicolumn{3}{|c|}{ Liquid media } & \multicolumn{3}{c|}{ Solid media } \\
\cline { 2 - 7 } & NFM & HsMS & FsMS & NFA & HsMS & FsMS \\
\hline \multirow{2}{*}{ B. argenteum } & $100 \%$ & $100 \%$ & $100 \%$ & $100 \%$ & $67 \%$ & $67 \%$ \\
\hline B. subapiculatum & $100 \%$ & $100 \%$ & $100 \%$ & $33 \%$ & $67 \%$ & $67 \%$ \\
\hline $\boldsymbol{P}$ hastata & $100 \%$ & $100 \%$ & $33 \%$ & $100 \%$ & $67 \%$ & $100 \%$ \\
\hline
\end{tabular}




\section{A Simple Method to Obtain Microbial-free in vitro Moss Cultures}

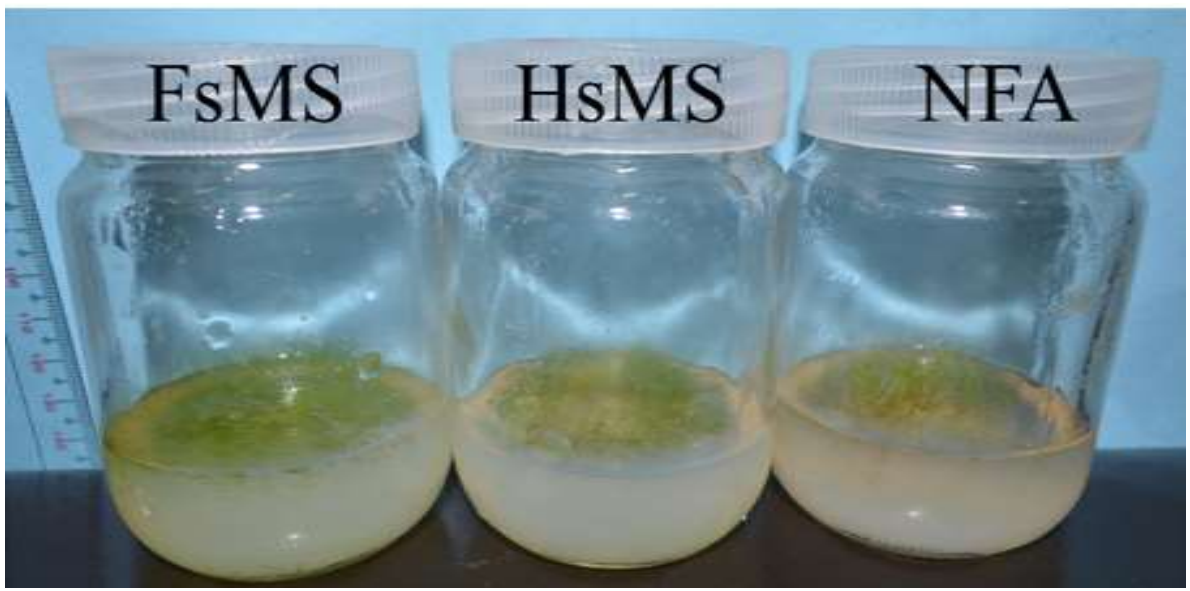

Fig. 1: Axenic cultures of Bryum argentum developed on solid media (NFA, HsMS \& FsMS) after incubation for 10 weeks.

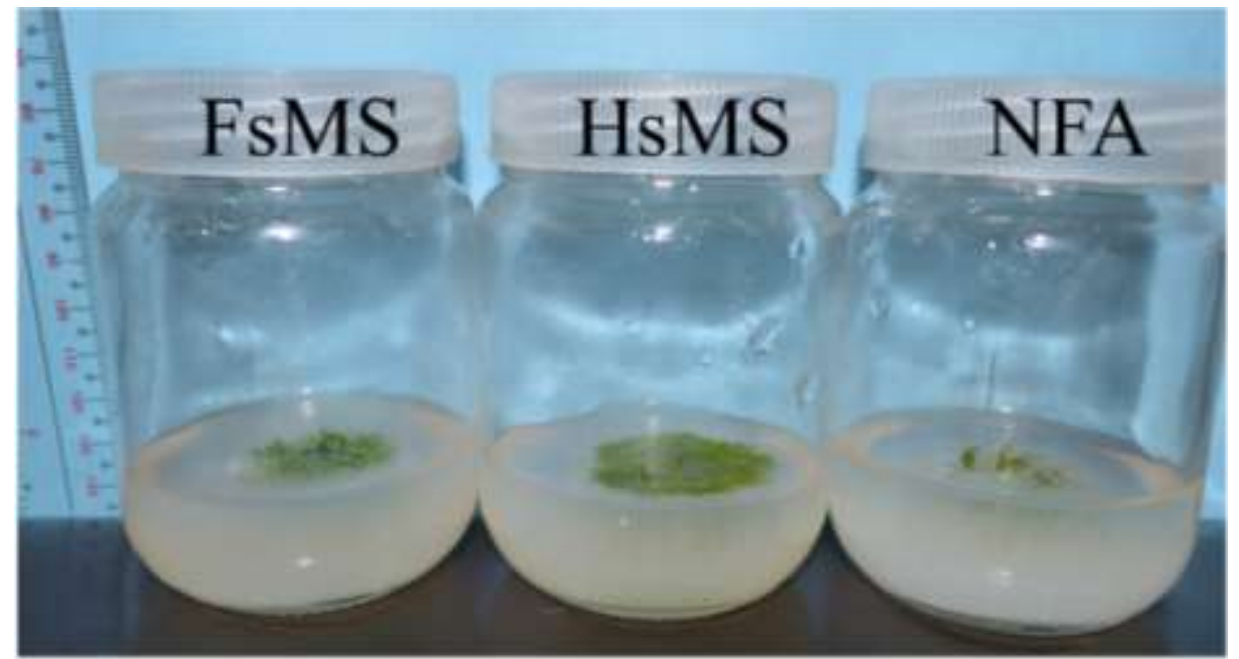

Fig. 2: Axenic cultures of Bryum subapiculatum developed on solid media (NFA, HsMS \& FsMS) after incubation for 10 weeks. 


\section{Hanan Shaaban et al.}

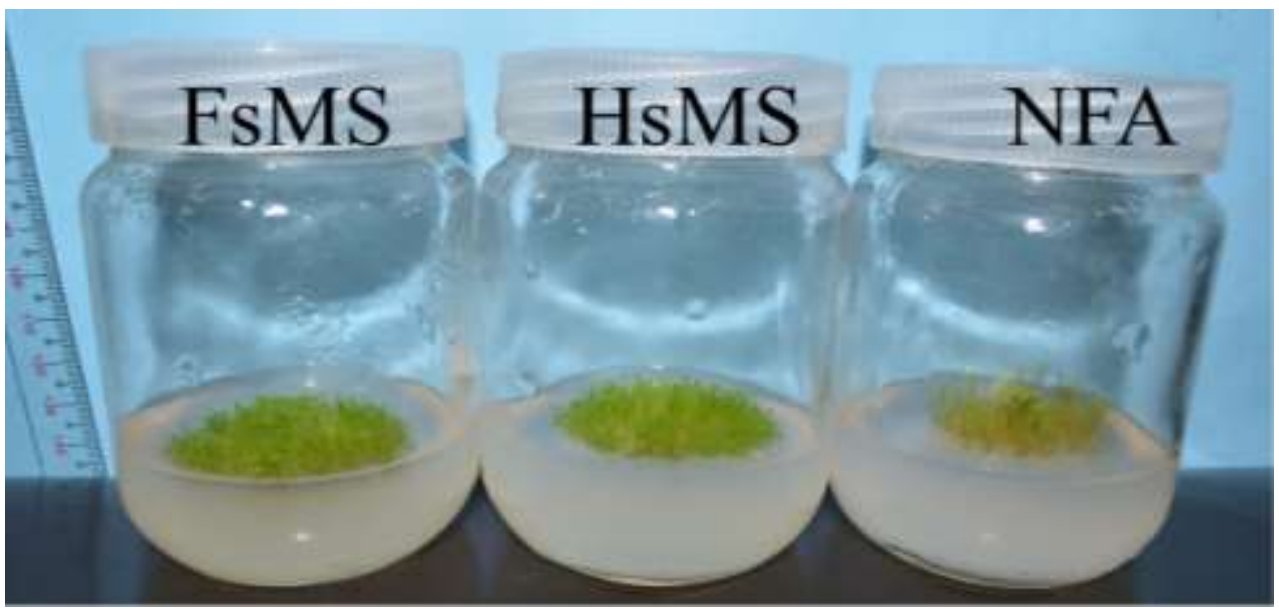

Fig. 3: Axenic cultures of Philonotis hastata developed on solid media (NFA, HsMS \& FsMS) after I ncubation for 10 weeks.

Although the changes from distended spore to filamentous protonema to gametophore buds can require increasingly more specialized conditions (Duckett et al. 2004, Glime 2007), yet the three species studied here exhibited normal development on all nutrient media as well as on NFM (solid or liquid) without any spicified requirements. This might be attributed to the high light intensity used in the plant growth chamber (9200 lux). It may be mentioned, in this context, that high light intensity and temperature promoted branching of caulonema, proliferated potential bud sites and provided a thicker mat in Hymenostylium, Campylopus and Physcomitrella (Glime, B.C. Knoop 1986, Mehta 1988).

Gametophores were observed earlier on NFA solid medium than with the other nutrient media, especially in case of $B$. argenteum. This might be attributed to that developed protonemata were mainly caulonemata filaments in NFA solid medium. As caulonema grows more rapidly than chloronema (Cove et al.
2006), the caulonema allows the developing plant to colonize on available substrate more rapidly (Cuming and Cuming 2008).

Protonemata of both B. argenteum and $P$. hastata started to develop in the $1^{\text {st }}$ week when cultured on HsMS and FsMS solid and liquid media, which agree with the results obtained for Physcomitrella patens (Hedw.) Bruch \& Schimp. (Decker and Reski 2004), B. argenteum (Liang et al. 2010), and Entosthodon hungaricus (Boros) Loeske (Sabovljevic et al. 2012). The present results, therefore, reflect the success of the developed modified technique.

On the other hand, the development of B. subapiculatum protonema was in the $1^{\text {st }}$ week only when cultured on HsMS solid medium but delayed to the $2^{\text {nd }}$ week with HsMS liquid medium and on FsMS solid and liquid media. Comparing growth rates of the three mosses in response to various nutrient concentrations showed that HsMS solid and liquid media were better for the growth than other media. It is known that moss species prefer dilute 


\section{A Simple Method to Obtain Microbial-free in vitro Moss Cultures}

culture solutions to concentrated ones (Awasthi et al. 2010). The concentrated media may even cause poor growth (Awasthi et al. 2012).

Thus, the modified technique developed in the present work for in vitro cultivation of $B$. argenteum, $B$. subapiculatum and $P$. hastata is an easy, inexpensive and successful technique which in worth extension for propagation, conservation and molecular studies of other species of mosses.

\section{References}

Awasthi, V. Nath,V. and Asthana, A.K. 2010. In vitro study on micropropagation and reproductive behaviour of moss Bryoerythrophyllum recurvirostrum (Hedw.) Chen. The International Journal of Plant Reproductive Biology, 2: 31-37.

Awasthi, V., Nath, V. , Pande, N. and Asthana, A.K.. 2012. Morphogenetic Studies and In vitro Propagation of Two Mosses: Philonotis thwaitesii Mitt. and Brachythecium plumosum (Hedw.) B.S.G., Taiwania, 57: 27-36.

Basile, D.V. 1972. Method for SurfaceSterilizing Small Plant Parts., Bulletin of the Torrey Botanical Club 99 : 313-316.

Basile, D.V. , Basile, M.R. 1988. Procedures used for the axenic culture and experimental treatment of bryophytes. , in: G. J.M. (ed.) Methods in Bryology: Proceedings of the bryological methods workshop, The Journal of the Hattori Botanical laboratory, Mainz., pp. $1-16$.

Becquerel, P. 1906. Germination des spores d' Atrichum undulatum et d' Hypnum velutinum. Nutrition et developpement de leurs protonema dans des milieux sterilises. Revue générale de Botanique 18: 49-67.
Beike, A.K. , Decker, E.L., Frank, W., Lang, D. , Scheebaum, M.V, Zimmer, A.D. and Reski,R. 2010. Applied Bryology- Bryotechnology, Tropical Bryology 31: 22-32.

Cano, M.J., Ros, R.M. and Guerra, J. 1996. In vitro culture of Pterigoneurum compactum (Musci, Pottiaceae): control of taxonomical characters., Cryptogamie Bryologie 17: 67-70.

Carey, S.B. , Payton, A.C. and McDaniel, S.F. 2015. A method for eliminating bacterial contamination from in vitro moss cultures, Applications in plant sciences.

Chen, Y.-Y. , Lou, Y.-X., Guo, S.-L and Cao, T. 2009. Successful Tissue Culture of the Medicinal Moss Rhodobryum giganteum and Factors Influencing Proliferation of Its Protonemata, Annales Botanici Fennici 46 :516-524.

Cove, D., Bezanilla, M. , Harries,P. and Quatrano, R. 2006. Mosses as model systems for the study of metabolism and development, Annual Review of plant biology 57: 497-520.

Cuming, A.C. and Cuming, A.C. 2008. Mosses as model organisms for developmental, cellular, and molecular biologyBryophyte Biology, Cambridge University Press.

Decker,E.L. and Reski,R. 2004. The moss bioreactor. Current opinion in plant biology 7: 166-170.

Duckett, J.G., Burch, J., Fletcher, P.W., Matcham, H.W., Read, D.J., Russell, A.J. and Pressel, S. 2004. In vitro cultivation of bryophytes: a review of practicalities, problems, progress and promise. Journal of Bryology 26 : 3-20.

Glime, J.M. 2007. Bryophyte Ecology. Michigan Technological University and 


\section{Hanan Shaaban et al.}

the International Association of Bryologists.

Glime, J.M. 2013. Sexual Strategies. in: J.M. Glime (ed.) Bryophyte Ecology. Michigan Technological University and the International Association of Bryologists.

Glime, J.M. and Knoop, B.C. 1986. Spore germination and protonemal development of Fontinalis squamosa. The Journal of the Hattori Botanical laboratory 61: 487-497.

Hedenäs, L. and Bisang, I. 2011. The overlooked dwarf males in mossesunique among green land plants, Perspectives in plant ecology. Evolution and Systematics, 13: 121-135.

Hohe, A. and Reski, R. 2005. From axenic spore germination to molecular farming. Plant cell reports 23: 513-521.

Lal, M. 1984. The culture of bryophytes including apogamy, apos- pory, parthenogenesis and protoplasts., in: A.F. Dyer, J.G. Duckett (Eds.) The Experimental Biology of Bryophytes. , Academic Press., London., pp. 97-115.

Liang, S.F., Sun, Y. and Zhu, R.-L. 2010. In vitro micropropagation of Bryum argenteum Hedw. Crypt Bryol 31: 233239.

Mehta, P. 1988. In vitro studies on spore germination, protonemal differentiation and bud formation in three mosses grown in vitro. The Journal of the Hattori Botanical laboratory 64:401-410.

Parkinson, M., Prendergast, M. and Sayegh, A. 1996. Sterilisation of explants and cultures with sodium dichloroisocyanurate, Plant Growth Regulation, 20: 61-66.
Niedz, R.P. and Bausher, M.G. 2002.

Control of in vitro contamination of explants from greenhouse-and fieldgrown trees, In Vitro Cellular \& Developmental Biology-Plant 38: 468471.

Peck, J.E., Muir, P.S. 2001. Harvestable epiphytic bryophytes and their accumulation in central western Oregon. The Bryologist 104: 181-190.

Reski, R. 1998. Development, genetics and molecular biology of mosses. Botanica Acta 111: 1-15.

Rowntree, J. 2006. Development of novel methods for the initiation of in vitro bryophyte cultures for conservation, Plant cell, tissue and organ culture 87:191-201.

Rowntree, J. and Ramsay, M. 2009. How bryophytes came out of the cold: successful cryopreservation of threatened species. Biodiversity and Conservation 18: 1413-1420.

Rowntree, J.K., Pressel, S., Ramsay, M.M., Sabovljevic, A. and M. Sabovljevic. 2011. In vitro conservation of European bryophytes, In Vitro Cellular \& Developmental Biology-Plant, 47: 5564.

Sabovljevic, M.S., Papp, B. , Sabovljević, A., Vujičić, M., Szurdoki, E. and J.G. Segarra-Moragues 2012. In vitro micropropagation of rare and endangered moss Entosthodon hungaricus (Funariaceae) = Micropropagação in vitro do musgo raro Entosthodon hungaricus, ameaçado de extinção (Funariaceae). Bioscience Journal, 28.

Sarasan, V., Cripps, R., Ramsay, M.M., Atherton, C., McMichen, M., Prendergast, G. and J.K. Rowntree 2006. Conservation in vitro of threatened 


\section{A Simple Method to Obtain Microbial-free in vitro Moss Cultures}

plants-progress in the past decade, In

Vitro Cellular \& Developmental Biology-

Plant 42: 206.

Victoria, F.C., Oliveira, A.C. and Peters, J.A. 2011. Establishment of the moss Polytrichum juniperinum Hedw. under axenic conditions. Bioscience Journal, Uberlandia 27:673-676.

Vöchting, H. 1885. Über die Regeneration der Marchantiaceen. , Jb Wiss Bot 16 : 367-414.

Vujičić, M., Sabovljević, A. and M. Sabovljević. 2009. Axenically culturing the bryophytes: a case study of the moss Dicranum scoparium Hedw. Dicranaceae, Bryophyta. Botanica Serbica 33: 137-1. 